\title{
Second intravenous immunoglobulin dose in patients with Guillain-Barré syndrome with poor prognosis (SID-GBS): a double-blind, randomised, placebo- controlled trial
}

Citation for published version (APA):

Walgaard, C., Jacobs, B. C., Lingsma, H. F., Steyerberg, E. W., van den Berg, B., Doets, A. Y., Leonhard, S. E., Verboon, C., Huizinga, R., Drenthen, J., Arends, S., Budde, I. K., Kleyweg, R. P., Kuitwaard, K., van der Meulen, M. F. G., Samijn, J. P. A., Vermeij, F. H., Kuks, J. B. M., van Dijk, G. W., ... van Doorn, P. A. (2021). Second intravenous immunoglobulin dose in patients with Guillain-Barré syndrome with poor prognosis (SID-GBS): a double-blind, randomised, placebo-controlled trial. Lancet Neurology, 20(4), 275283. https://doi.org/10.1016/S1474-4422(20)30494-4

Document status and date:

Published: 01/04/2021

DOI:

10.1016/S1474-4422(20)30494-4

Document Version:

Publisher's PDF, also known as Version of record

Document license:

Taverne

Please check the document version of this publication:

- A submitted manuscript is the version of the article upon submission and before peer-review. There can be important differences between the submitted version and the official published version of record. People interested in the research are advised to contact the author for the final version of the publication, or visit the DOI to the publisher's website.

- The final author version and the galley proof are versions of the publication after peer review.

- The final published version features the final layout of the paper including the volume, issue and page numbers.

Link to publication

\footnotetext{
General rights rights.

- You may freely distribute the URL identifying the publication in the public portal. please follow below link for the End User Agreement:

www.umlib.nl/taverne-license

Take down policy

If you believe that this document breaches copyright please contact us at:

repository@maastrichtuniversity.nl

providing details and we will investigate your claim.
}

Copyright and moral rights for the publications made accessible in the public portal are retained by the authors and/or other copyright owners and it is a condition of accessing publications that users recognise and abide by the legal requirements associated with these

- Users may download and print one copy of any publication from the public portal for the purpose of private study or research.

- You may not further distribute the material or use it for any profit-making activity or commercial gain

If the publication is distributed under the terms of Article 25fa of the Dutch Copyright Act, indicated by the "Taverne" license above,

Download date: 26 Apr. 2023 


\title{
Second intravenous immunoglobulin dose in patients with Guillain-Barré syndrome with poor prognosis (SID-GBS): a double-blind, randomised, placebo-controlled trial
}

\author{
Christa Walgaard, Bart C Jacobs, Hester F Lingsma, Ewout W Steyerberg, Bianca van den Berg, Alexandra Y Doets, Sonja E Leonhard, \\ Christine Verboon, Ruth Huizinga, Judith Drenthen, Samuel Arends, Ilona Kleine Budde, Ruud P Kleyweg, Krista Kuitwaard, \\ Marjon F G van der Meulen, Johnny P A Samijn, Frederique H Vermeij, Jan B M Kuks, Gert W van Dijk, Paul W Wirtz, Filip Eftimov, \\ Anneke J van der Kooi, Marcel PJ Garssen, Cees J Gijsbers, Maarten C de Rijk, Leo H Visser, RoderikJ Blom, Wim HJ P Linssen, Elly L van der Kooi, \\ Jan J G M Verschuuren, Rinske van Koningsveld, Rita J G Dieks, H Job Gilhuis, KornéJellema, Taco C van der Ree, Henriette M E Bienfait, \\ Catharina G Faber, Harry Lovenich, Baziel G M van Engelen, RutgerJ Groen, Ingemar SJ Merkies, Bob W van Oosten, W Ludo van der Pol, \\ Willem D M van der Meulen, Umesh A Badrising, Martijn Stevens, Albert-Jan J Breukelman, Casper P Zwetsloot, Maaike M van der Graaff, \\ Marielle Wohlgemuth, Richard A C Hughes, David R Cornblath, Pieter A van Doorn, on behalf of the Dutch GBS Study Group*
}

\section{Summary}

Background Treatment with one standard dose $(2 \mathrm{~g} / \mathrm{kg})$ of intravenous immunoglobulin is insufficient in a proportion of patients with severe Guillain-Barré syndrome. Worldwide, around $25 \%$ of patients severely affected with the syndrome are given a second intravenous immunoglobulin dose (SID), although it has not been proven effective. We aimed to investigate whether a SID is effective in patients with Guillain-Barré syndrome with a predicted poor outcome.

Methods In this randomised, double-blind, placebo-controlled trial (SID-GBS), we included patients ( $\geq 12$ years) with Guillain-Barré syndrome admitted to one of 59 participating hospitals in the Netherlands. Patients were included on the first day of standard intravenous immunoglobulin treatment $(2 \mathrm{~g} / \mathrm{kg}$ over 5 days). Only patients with a poor prognosis (score of $\geq 6$ ) according to the modified Erasmus Guillain-Barré syndrome Outcome Score were randomly assigned, via block randomisation stratified by centre, to SID (2 g/kg over 5 days) or to placebo, 7-9 days after inclusion. Patients, outcome adjudicators, monitors, and the steering committee were masked to treatment allocation. The primary outcome measure was the Guillain-Barré syndrome disability score 4 weeks after inclusion. All patients in whom allocated trial medication was started were included in the modified intention-to-treat analysis. This study is registered with the Netherlands Trial Register, NTR 2224/NL2107.

Findings Between Feb 16, 2010, and June 5, 2018, 327 of 339 patients assessed for eligibility were included. 112 had a poor prognosis. Of those, 93 patients with a poor prognosis were included in the modified intention-to-treat analysis: $49(53 \%)$ received SID and $44(47 \%)$ received placebo. The adjusted common odds ratio for improvement on the Guillain-Barré syndrome disability score at 4 weeks was 1.4 (95\% CI $0 \cdot 6-3 \cdot 3 ; p=0 \cdot 45)$. Patients given SID had more serious adverse events (35\% vs $16 \%$ in the first 30 days), including thromboembolic events, than those in the placebo group. Four patients died in the intervention group (13-24 weeks after randomisation).

Interpretation Our study does not provide evidence that patients with Guillain-Barré syndrome with a poor prognosis benefit from a second intravenous immunoglobulin course; moreover, it entails a risk of serious adverse events. Therefore, a second intravenous immunoglobulin course should not be considered for treatment of Guillain-Barre syndrome because of a poor prognosis. The results indicate the need for treatment trials with other immune modulators in patients severely affected by Guillain-Barré syndrome.

Funding Prinses Beatrix Spierfonds and Sanquin Plasma Products.

Copyright (C) 2021 Elsevier Ltd. All rights reserved.

\section{Introduction}

Guillain-Barré syndrome is an immune-mediated polyradiculoneuropathy, which affects $0.81-1.89$ per 100000 people annually worldwide. ${ }^{1}$ Guillain-Barré syndrome is usually a monophasic disease with rapidly progressive limb weakness. ${ }^{2}$ The clinical severity, course, and outcome are variable. ${ }^{1}$ Intravenous immunoglobulin and plasma exchange are proven effective treatments. ${ }^{3,4}$ Even with standard intravenous immunoglobulin treatment, about $20 \%$ of patients remain unable to walk after 6 months. In $20-30 \%$ of patients, mechanical ventilation is needed, 3-7\% die, and many have persistent residual complaints such as fatigue and pain. ${ }^{5}$ Patients with a poor prognosis early in their disease course might gain particular benefit from additional treatment. A second intravenous immunoglobulin dose (SID), administered early in the course of disease, before severe or irreversible nerve damage has occurred, might be

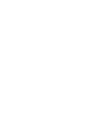

Lancet Neurol 2021; 20: $275-$
See Comment page 249

*A complete list of investigators in the SID-GBS trial is provided in the appendix ( $p 2$ )

Department of Neurology (CWalgaard MD,

Prof $B C$ Jacobs $M D$ $B$ van den Berg MD, $A$ Y Doets MD, S E Leonhard MD CVerboon MD, J Drenthen MD, S Arends MD, K Kuitwaard MD, Prof PA van Doorn MD) Department of Immunology (Prof B C Jacobs,

$R$ Huizinga $P h D)$, and Department of Public Health (H F Lingsma PhD,

Prof EW Steyerberg PhD), Erasmus MC University Medical Center, Rotterdam, Netherlands; Department of Biomedical Data Sciences, (Prof EW Steyerberg) and Department of Neurology (Prof J) G M Verschuuren MD U A Badrising MD), Leiden University Medical Center, Leiden, Netherlands; Department of Neurology, Elisabeth-TweeSteden Hospital, Tilburg, Netherlands (B van den Berg, Prof L H Visser MD, M Wohlgemuth MD); The Medical Department Sanquin Plasma Products, Amsterdam, Netherlands (I K Budde PhD); Department of Neurology, Albert Schweitzer Hospital Dordrecht, Netherlands (R P Kleyweg MD, K Kuitwaard); Department of Neurology, Sint Antonius Hospital, Nieuwegein, Netherlands (M F G van der Meulen MD); Department of Neurology, Maasstad Hospital, Rotterdam, Netherlands (J PA Samijn MD); 
Department of Neurology, Franciscus en Vlietland Hospital, Rotterdam, Netherlands (F H Vermeij MD, C) Gijsbers MD), Department of Neurology, University Medical Center Groningen, Groningen, Netherlands (Prof) B M Kuks MD): Department of Neurology, Canisius Wilhelmina Hospital, Nijmegen, Netherlands (GW van Dijk MD); Department of Neurology, Haga Hospital, Den Haag, Netherlands (PW Wirtz MD); Department of Neurology, Amsterdam UMC, University of Amsterdam, Amsterdam, Netherlands (F Eftimov MD,

A J van der Kooi MD); Department of Neurology, Jeroen Bosch hospital, Den Bosch, Netherlands (M P J Garssen MD); Department of Neurology, Catharina

Hospital, Eindhoven,

Netherlands (M C de Rijk MD); Department of Neurology, Diakonessenhuis, Utrecht, Netherlands (RJ Blom MD); Department of Neurology, Onze Lieve Vrouwen Gasthuis-West, Amsterdam, Netherlands (W H J P Linssen MD); Zaans Medical Center, Zaandam,

Netherlands (W H J P Linssen); Department of Neurology, Leeuwarden Medical Center, Leeuwarden, Netherlands

( $\mathrm{L}$ van der Kooi MD);

Department of Neurology,

Elkerliek Hospital, Helmond, Netherlands

(R van Koningsveld MD); Department of Neurology,

Röpke-Zweers Hospital, Hardenberg, Netherlands

(R J G Dieks MD); Department of Neurology, Reinier de Graaf Hospital, Delft, Netherlands (HJ Gilhuis MD); Department of

Neurology, Haaglanden Medical Center, Den Haag, Netherlands (K Jellema MD,

RJ Groen MD); Department of Neurology, Dijklander hospital, Hoorn, Netherlands ( $T$ C van der Ree MD); Department of Neurology, Spaarne Gasthuis, Haarlem, Netherlands (H M E Bienfait MD,

ISJ Merkies MD); Department of Neurology, Maastricht University Medical Center,

Maastricht, Netherlands (Prof C G Faber MD, I S J Merkies);

Department of Neurology,

St Jans Hospital, Weert, Netherlands (H Lovenich MD);

\section{Research in context}

\section{Evidence before this study}

A PubMed search for articles in English, published from database inception up until May 22, 2020, for "[Guillain-Barré syndrome], and [second IVIg course]", "[Guillain-Barré syndrome], and [repeated intravenous immunoglobulin]", and "[Guillain-Barré syndrome], and [second cycle immunoglobulin]" identified four case reports, two case series, and one observational study in which additional intravenous immunoglobulin treatment was investigated in patients with Guillain-Barré syndrome with a severe disease course. The case reports and case series ( $n=11)$ suggested additional benefit from a second intravenous immunoglobulin course. The observational study based on patients with Guillain-Barré syndrome enrolled in the international Guillain-Barré syndrome outcome study selected patients with a poor predicted outcome according to the modified Erasmus GBS Outcome Scale prognostic model. No difference in outcome was found between patients given one intravenous immunoglobulin course ( $n=199)$ or two intravenous immunoglobulin courses $(n=38)$. None of these studies reported complications possibly attributable to the additional intravenous immunoglobulin treatment. Not all patients in these studies received an early second intravenous immunoglobulin course and publication bias could have played an important role in the positive findings.

beneficial, although there is scant evidence to support this approach. ${ }^{6,7}$

In current practice, about a quarter of patients with Guillain-Barré syndrome given intravenous immunoglobulin who show no clinical improvement are re-treated with intravenous immunoglobulin. This practice could be based on results from a small uncontrolled case series of patients with severe Guillain-Barré syndrome and a phase 2 trial suggesting that a higher dose of intravenous immunoglobulin was more beneficial than a lower dose. ${ }^{8-10}$ Another argument that repeated intravenous immunoglobulin doses might be effective comes from the observation that about $10 \%$ of patients with Guillain-Barré syndrome have a so-called treatment-related fluctuation, which seems to respond to a SID. ${ }^{11}$ Additionally, patients have a variable increase in serum IgG concentration after a standard dose of intravenous immunoglobulin, and a low IgG increase is associated with poor outcome, indicating that these patients might benefit from additional intravenous immunoglobulin treatment. ${ }^{12}$ However, intravenous immunoglobulin is costly; moreover uncommon severe side-effects might be more frequent when administered repeatedly. We aimed to evaluate the effect of SID in patients with Guillain-Barré syndrome with poor prognosis.

\section{Methods}

\section{Study design and participants}

We did a double-blind, randomised, placebo-controlled phase 3 trial (SID-GBS) in patients with Guillain-Barre

\section{Added value of this study}

The SID-GBS trial is the first randomised, placebo-controlled double-blind trial investigating the added value of a second intravenous immunoglobulin course in patients with Guillain-Barré syndrome with a poor predicted outcome, to our knowledge. The study showed that a second intravenous immunoglobulin course in these patients does not have a clinically meaningful benefit for recovery. All secondary endpoints did not differ between treatment groups. This trial was the first controlled study to show a possible harmful effect of a second intravenous immunoglobulin course.

Implications of all the available evidence

A second intravenous immunoglobulin course in patients with Guillain-Barré syndrome with a poor prognosis is not recommended. The results are based on the absence of evidence for a better outcome and on the higher frequency of serious adverse events, including severe thromboembolic complications. Although the absence of evidence does not equate to evidence of ineffectiveness, it is very unlikely that a second intravenous immunoglobulin course will have a clinically relevant positive effect.

syndrome with a poor prognosis. The protocol of this trial has been published. ${ }^{13}$ Patients were included from 59 hospitals in the Netherlands (a list of participating centres and number of inclusions per centre is available in the appendix (p 17). Patients aged 12 years or older, diagnosed with Guillain-Barré syndrome, and with an indication for intravenous immunoglobulin treatment according to the treating neurologist, were potentially eligible for inclusion in the trial. ${ }^{2}$ Full eligibility criteria are available in the appendix ( $\mathrm{p} 18$ ).

Patients were randomly allocated (1:1) to receive SID or placebo for 5 days, which was administered at 7-9 days after the start of the first standard intravenous immunoglobulin treatment $(2 \mathrm{~g} / \mathrm{kg}$ administered over 5 consecutive days). Interim monitoring was done after 36 randomisations.

All patients (poor and good prognosis) were included on the first day of their standard intravenous immunoglobulin treatment. We used the modified Erasmus GBS Outcome Scale (mEGOS) 7-9 days after start of the standard intravenous immunoglobulin dose to select patients with a poor prognosis. ${ }^{6}$ Only patients with a poor prognosis were randomly assigned to SID or placebo. The mEGOS prognostic model ranges from 0 (best prognosis) to 12 (worst prognosis) and uses age, preceding diarrhoea, and the Medical Research Council (MRC) sumscore ${ }^{14}$ as clinical predictors of outcome (appendix pp 9, 19). ${ }^{6}$ In this trial, an mEGOS of six or more was used as the cutoff for poor prognosis. Using this cutoff, we expected to 
select about $50 \%$ of the included patients for random assignment.

The trial was approved by the ethics committee of all participating centres, and all patients provided written informed consent before random assignment.

\section{Randomisation and masking}

A web-based computerised random number generator from an external party (Clinical Trial Centre Maastricht) allocated treatment in a 1:1 ratio by block randomisation (six patients per block with the block size unknown to local sites), stratified according to participating centre. Placebo (albumin) was matched to the study drug by volume $(8 \mathrm{~mL} / \mathrm{kg}$ ) and fluid aspect (due to proteins in intravenous immunoglobulin and albumin, both are slightly foaming liquids). As the colour of intravenous immunoglobulin can differ between batches, the bag (ethylene vinyl acetate) containing the trial medication was concealed using aluminum foil and opaque connecting lines were used to mask study staff. Patients, outcome adjudicators, monitors, and the steering committee were masked to treatment allocation.

\section{Procedures}

Patients with a poor prognosis were randomly assigned to receive either SID (Nanogam $50 \mathrm{mg} / \mathrm{mL}$, Sanquin Plasma Products, Amsterdam, Netherlands) or placebo (albumin 4\%, pasteurised plasma protein solution until June, 2012, and Albuman $40 \mathrm{~g} / \mathrm{L}$ from June, 2012, onwards, Sanquin Plasma Products) in a dose of $8 \mathrm{~mL} / \mathrm{kg}$, both for 5 days. Patients with a good prognosis (mEGOS 0-5) were not randomly assigned, but had otherwise the same follow-up and outcome parameters assessment as the randomly assigned participants. All patients underwent clinical assessments at the start of standard intravenous immunoglobulin treatment; at week 1 (randomisation); weeks 2 and 4 (primary endpoint); and weeks 8,12 , and 26 after start of standard intravenous immunoglobulin treatment. Adverse events were assessed at every study visit. At study entry, blood was collected and serum was stored for detection of antiganglioside antibodies, antibodies to cytomegalovirus, Epstein-Barr virus, hepatitis E, and Campylobacter jejuni using routine diagnostic assays. ${ }^{15-18}$ Also IgG and albumin concentrations were measured in serial serum samples (baseline, 1, 2, 4, and 13 weeks). Nerve conduction studies were reviewed in the coordinating centre by two masked trial electrophysiologists (JD and SA) and classified according to the Hadden criteria. ${ }^{19}$ All patients were given standard supportive care as recommended by guidelines, including low molecular weight heparin. ${ }^{20}$

\section{Outcomes}

The primary outcome was Guillain-Barré syndrome disability scale ${ }^{21}$ score at 4 weeks after the start of standard intravenous immunoglobulin treatment. This disability

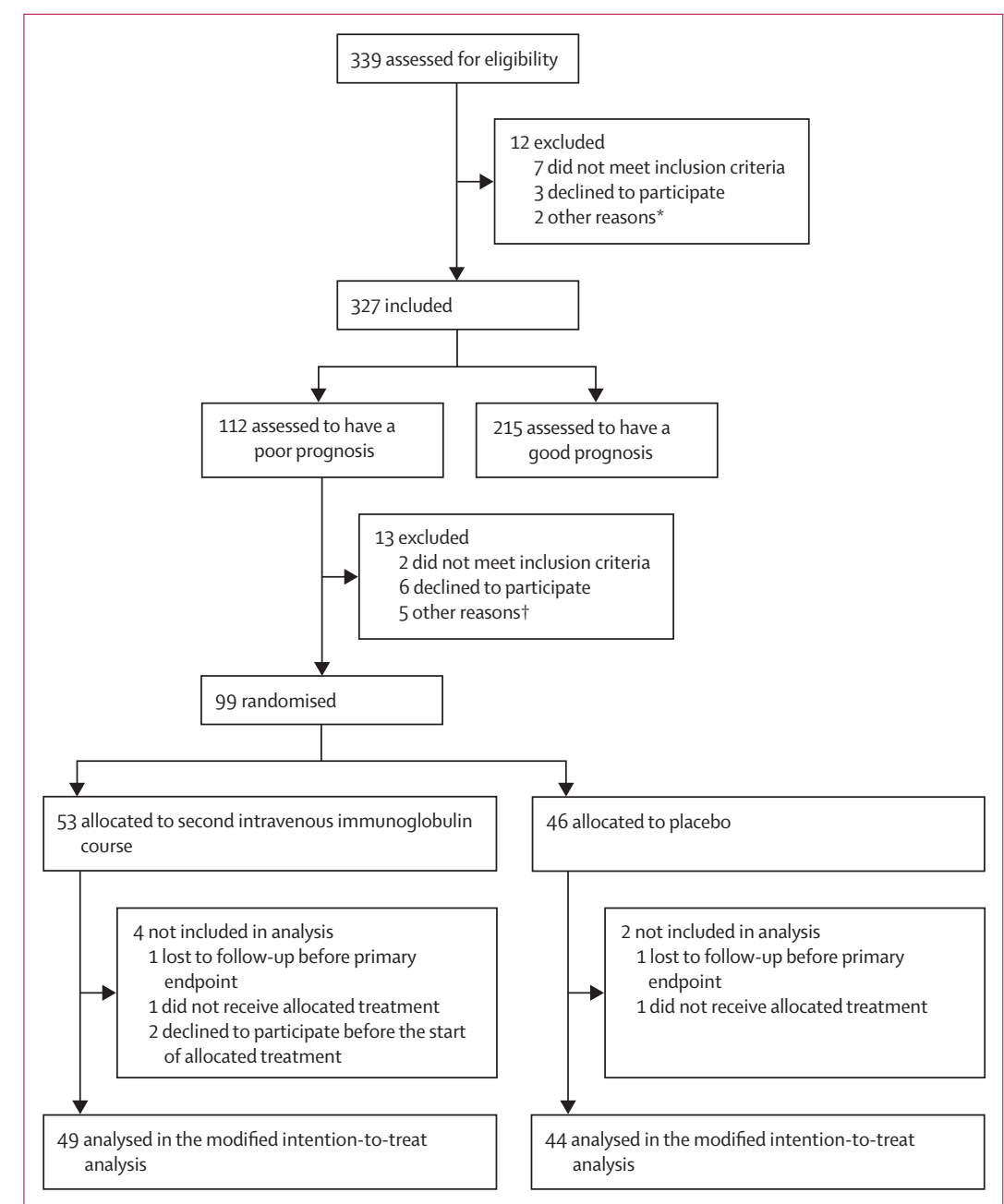

Figure 1: Trial profile

*Other refers to transfer to hospital abroad or pharmacy not prepared to deliver allocated treatment. †Other refers to receiving open second intravenous immunoglobulin dose before random assignment, erroneously marked as good prognosis $(n=3)$, or case report files lost in participating hospital.

scale is the most frequently used clinical outcome measure in Guillain-Barré syndrome trials. It is a seven-point scale ranging from 0 (no symptoms) to 6 (death). ${ }^{4}$ Prespecified secondary outcomes were assessed at weeks 4, 8, 12, and 26, and comprised the Guillain-Barré syndrome disability scale, ${ }^{21}$ improvement of at least one grade on the Guillain-Barré syndrome disability scale, ${ }^{21}$ the MRC sumscore ${ }^{14}$ the Overall Neuropathy Limitations Scale, ${ }^{22}$ the percentage of patients needing artificial ventilation, duration of artificial ventilation, intensive care admission and hospital admission, mortality, percentage of treatment-related fluctuations, and serum IgG concentrations at subsequent timepoints. Adverse events and serious adverse events were collected by treating physicians, according to the International Conference on Harmonization Good Clinical Practice guidelines, and compared between the randomised groups using descriptive statistics.
Department of Neurology, Radboud University Medical Center, Nijmegen, Netherlands (Prof B G M van Engelen MD); Department of Neurology, Amsterdam University Medical Centers, VUmc Amsterdam, Netherlands (Prof B W van Oosten MD); Department of Neurology, University Medical Center Utrecht, Utrecht, Netherlands (Prof W L van der Pol MD); Department of Neurology, Rode Kruis Hospital, Beverwijk, Netherlands (W D M van der Meulen MD); Department of Neurology, van Weel-Bethesda Hospital, Dirksland, Netherlands (U A Badrising); Department of Neurology, Tergooi Hospitals, 


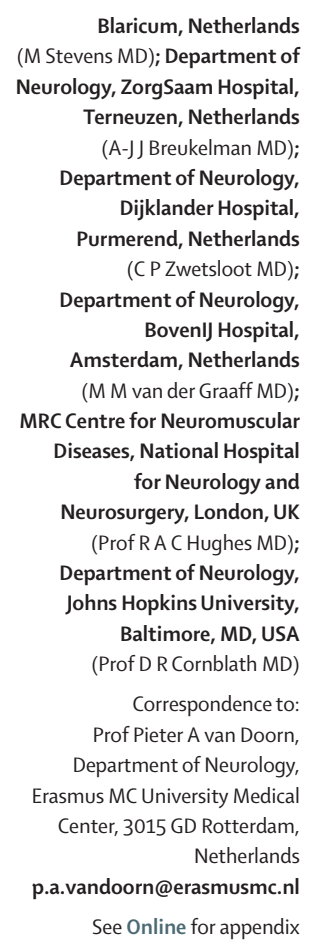

\begin{tabular}{|c|c|c|}
\hline & $\operatorname{SID}(n=49)$ & Placebo $(n=44)$ \\
\hline Age, years & $66 \cdot 0(59 \cdot 5-74 \cdot 0)$ & $59 \cdot 0(42 \cdot 5-70 \cdot 0)$ \\
\hline \multicolumn{3}{|l|}{ Sex } \\
\hline Women & $18(37 \%)$ & $10(23 \%)$ \\
\hline Men & $31(63 \%)$ & $34(77 \%)$ \\
\hline Preceding diarrhoea* & $24(49 \%)$ & $14(32 \%)$ \\
\hline \multicolumn{3}{|c|}{ Disability score at randomisation } \\
\hline 3 & $1(2 \%)$ & $1(2 \%)$ \\
\hline 4 & $28(57 \%)$ & $23(52 \%)$ \\
\hline 5 & $20(41 \%)$ & $20(45 \%)$ \\
\hline $\begin{array}{l}\text { MRC sumscore at } \\
\text { randomisation, 0-60 }\end{array}$ & $23(6-38)$ & $26(12-35)$ \\
\hline \multicolumn{3}{|l|}{ Nerve conduction studies $\dagger$} \\
\hline Demyelinating & $31(63 \%)$ & $29(66 \%)$ \\
\hline Axonal & $2(4 \%)$ & $2(5 \%)$ \\
\hline Equivocal & $7(14 \%)$ & $4(9 \%)$ \\
\hline Inexcitable & $7(14 \%)$ & $4(9 \%)$ \\
\hline $\begin{array}{l}\text { Not performed or } \\
\text { unjudgable }\end{array}$ & $2(4 \%)$ & $5(11 \%)$ \\
\hline $\begin{array}{l}\text { Positive Campylobacter } \\
\text { jejuni serology } \ddagger\end{array}$ & $16(33 \%)$ & $10 / 42(24 \%)$ \\
\hline \multicolumn{3}{|c|}{ Antiganglioside $\lg \mathrm{M}$ or $\lg G$ antibodies } \\
\hline GM1 & $15 / 48(31 \%)$ & $11 / 42(26 \%)$ \\
\hline GD1a & $5 / 48(10 \%)$ & $4 / 42(10 \%)$ \\
\hline $\begin{array}{l}\text { Mean serum delta lgG } \\
\text { concentration, g/LS }\end{array}$ & $\begin{array}{l}16 \cdot 1 \\
(95 \% \mathrm{Cl} 13 \cdot 6-18 \cdot 5)\end{array}$ & $\begin{array}{l}18 \cdot 4 \\
(95 \% \mathrm{Cl} 15 \cdot 7-21 \cdot 1)\end{array}$ \\
\hline $\begin{array}{l}\text { Mean serum albumin } \\
\text { concentration after } \\
\text { intravenous } \\
\text { immunoglobulin, g/dLף }\end{array}$ & $\begin{array}{l}32 \cdot 5 \\
(95 \% \text { Cl 30.7-34.3) }\end{array}$ & $\begin{array}{l}35 \cdot 1 \\
(95 \% \mathrm{Cl} 33 \cdot 5-36 \cdot 7)\end{array}$ \\
\hline \multicolumn{3}{|c|}{$\begin{array}{l}\text { Data are median (IQR), } \mathrm{n}(\%) \text {, or } \mathrm{n} / \mathrm{N}(\%) \text {, unless specified. SID=second intravenous } \\
\text { immunoglobulin dose. MRC=Medical Research Council. *Diarrhoea in the } 4 \text { weeks } \\
\text { preceding the onset of weakness. †According to the Hadden criteria. }{ }^{19} \neq \text { Data were } \\
\text { missing for two patients in the placebo group. } S \text { Value } 1 \text { week after start of the first } \\
\text { standard intravenous immunoglobulin dose: baseline (pre-treatment) or, when } \\
\text { missing, } 3 \text { months after intravenous immunoglobulin treatment. } \text { IData were } \\
\text { missing for five patients in the intervention group and five patients in the } \\
\text { control group. }\end{array}$} \\
\hline
\end{tabular}

\section{Statistical analysis}

We assumed that a $20 \%$ difference in the proportion of patients improving at least one grade on the Guillain-Barré syndrome disability scale between the patients with and without SID treatment 4 weeks after the start of standard intravenous immunoglobulin treatment would be clinically relevant. Without covariate adjustment and ordinal outcome analysis, we needed to randomly assign 145 patients with a poor prognosis $(\alpha=0 \cdot 05$, power $0 \cdot 80)$ to detect this difference. We expected covariate adjustment and ordinal outcome analysis to result in a reduction in required sample size of $40-50 \% .{ }^{23}$ This expectation reduced the required sample size to between 73 and 88 patients. ${ }^{13}$

The primary analysis was modified intention to treat, in which all randomly assigned patients in whom allocated trial medication was started were included. The primary efficacy outcome was estimated with a proportional odds regression analysis. ${ }^{2425}$ For both primary and secondary endpoints, prespecified covariate adjustment was done to adjust for variation in baseline prognostic risk between patients. We adjusted for age, preceding diarrhoea, and MRC sumscore at randomisation. ${ }^{13,26}$ This adjustment resulted in an adjusted common odds ratio for the effect of treatment with a $95 \% \mathrm{CI}$ and corresponding $\mathrm{p}$ value. A two-tailed $\mathrm{p}$ value of less than 0.05 was considered statistically significant. Multiple imputation was applied to account for missing values in covariates and secondary endpoints; the primary endpoint was not imputed. There was no adjustment for multiple comparisons of secondary outcomes and these are presented as point estimates with unadjusted $95 \%$ CIs, from which no inferences can be made. Treatment-effect modification was explored in prespecified subgroups of patients as defined in the appendix ( $\mathrm{p} 7$ ). A trial data safety and monitoring board overlooked the trial and interim monitoring was done after 36 randomisations. This study is registered with the Netherlands Trial Register, NTR 2224/NL2107 and the statistical analysis plan was published here before unblinding the trial data. Analyses were done using $\mathrm{R}$ Studio version 3.6.1.

\section{Role of the funding source}

The funder of the study had no role in study design, data collection, data analysis, data interpretation, or writing of the report.

\section{Results}

Between Feb 16, 2010, and June 5, 2018, 327 of 339 patients assessed for eligibility with Guillain-Barré syndrome were included (figure 1). 12 were excluded before $\mathrm{mEGOS}$ could be determined at days 7-9 (figure 1). $215 \mathrm{had}$ a good prognosis (mEGOS $<6)$, and $112 \mathrm{had}$ a poor prognosis $(\mathrm{mEGOS} \geq 6)$. $13(12 \%)$ of the 112 patients with a poor prognosis were excluded before random assignment (mainly because of withdrawal of consent). Of the 99 randomly assigned patients, 53 (54\%) were assigned to the SID group and $46(46 \%)$ to the placebo group. Six patients were excluded after random assignment: two declined to participate before the start of allocated treatment, two patients did not receive the allocated treatment, and two patients were lost to follow-up shortly after randomisation when it became clear that they had an alternative diagnosis (one case of eosinophilic vasculitis in the placebo group and one case of myelopathy in the SID group). Of these patients, four had been assigned to SID and two had been assigned to placebo (figure 1). In the modified intention-to-treat analysis, 49 (53\%) patients received SID and 44 (47\%) received placebo.

Almost all patients who had been randomly assigned had severe weakness (as assessed with the MRC sumscore and Guillain-Barré syndrome disability score) and $85 \%$ were still deteriorating at 1 week according to the MRC sumscore, despite a standard intravenous immunoglobulin course (appendix pp 14-16). 
Predictors of poor outcome were not evenly distributed between the two groups. Typically, patients in the SID group were older and had preceding diarrhoea more commonly than those in the placebo group (table 1, appendix p 12). Prespecified covariate adjustment was done for known prognostic factors.

Data for the primary outcome were complete (table 2). The adjusted common odds ratio for improvement on the Guillain-Barré syndrome disability score at 4 weeks was 1.4 (95\% CI $0.6-3 \cdot 3$; $\mathrm{p}=0.45$; figure 2 , table 2 ). The unadjusted common odds ratio was $1 \cdot 3$ (95\% CI 0 6-3 - 3). There was no evidence of a difference between treatment groups for any of the secondary outcomes. Guillain-Barré syndrome disability scores at weeks 8,12 , and 26 did not differ between groups (appendix p 16). Additionally, the probability of improving one grade or more on the Guillain-Barré syndrome disability scale at four different timepoints did not differ between groups. The MRC sumscore and Overall Neuropathy Limitations Scale were not different between groups at weeks 4, 8, 12, and 26 (appendix pp 14-15). Duration of hospital admission, intensive care unit admission, and mechanical ventilation were not different between groups (table 2, appendix p 11). Outcomes in the prespecified subgroups did not differ between treatment groups (figure 3). Patients with a good prognosis ( $\mathrm{n}=208$, seven excluded) had a median GuillainBarré syndrome disability score of 2 (IQR 2-3) at 4 weeks, $1(1-2)$ at 12 weeks, and $1(0-2)$ at 26 weeks, indicating a generally good outcome in this group.

Four patients died during the trial, all of whom were assigned to SID. The deaths included a 59-year-old man who was previously healthy before developing GuillainBarré syndrome, who died 16 weeks after random assignment due to asystole that was deemed possibly related to a serious adverse event (acute coronary syndrome), which occurred 4 days after administration of SID. An 82-year-old woman died 13 weeks after randomisation due to discontinuation of artificial ventilation at the request of the patient, after no signs of improvement, multiple complications, and severe pain. A 72-year-old woman died 21 weeks after randomisation from a cardiac cause in a nursing home. An 81-year-old woman died 24 weeks after randomisation, because of discontinuation of artificial ventilation at the request of the patient after no signs of improvement, and multiple complications. Serious adverse events, including thromboembolic events, occurred more often in the SID group than the placebo group (51\% vs 23\%, table 3 , appendix p 12). Trial medication was not completed in two cases due to adverse events (ophthalmoplegia due to pituitary adenoma after placebo and severe skin rash after SID). From 2015 onward, randomly assigned patients (24 [26\%] of 93) were tested for haemolytic anaemia after a protocol amendment based on a report about this possible adverse event in high-dose intravenous immunoglobulin treatment, but this adverse event was not seen in our trial. ${ }^{27}$

In the SID group, serum IgG was maintained at a high concentration longer than in the placebo group (median

\begin{tabular}{|c|c|c|c|}
\hline & $\operatorname{SID}(n=49)$ & Placebo $(n=44)$ & $\begin{array}{l}\text { Adjusted common } \\
\text { odds ratio }(95 \% \mathrm{Cl})\end{array}$ \\
\hline \multicolumn{4}{|l|}{ Primary outcome } \\
\hline Disability score at 4 weeks & $4(4-5)$ & $4(4-5)$ & $1.4(0.6$ to $3 \cdot 3)$ \\
\hline \multicolumn{4}{|l|}{ Secondary outcomes } \\
\hline Disability score at 8 weeks & $4(3-4)$ & $4(2-4)$ & $1.5(0.7$ to $3 \cdot 3)$ \\
\hline Disability score at 12 weeks & $3(2-3)$ & $3(2-3)$ & $2.1(0.9$ to 4.6$)$ \\
\hline Disability score at 26 weeks & $2(1-4)$ & $2(1-3)$ & $1.0(0.5$ to $2 \cdot 2)$ \\
\hline \multicolumn{4}{|l|}{ Disability score improvement ( $\geq 1$ point) } \\
\hline 4 weeks & $18(37 \%)$ & $12(27 \%)$ & $1.8(0.6$ to $5 \cdot 3)$ \\
\hline 8 weeks & $27(55 \%)$ & $26(59 \%)$ & $1.0(0.4$ to 2.5$)$ \\
\hline 12 weeks & $36(73 \%)$ & $34(77 \%)$ & $1.7(0.5$ to 5.4$)$ \\
\hline 26 weeks & $40(82 \%)$ & $41(93 \%)$ & $0.4(0.1$ to $2 \cdot 6)$ \\
\hline \multicolumn{4}{|l|}{ ONLS score } \\
\hline 4 weeks & $10(8-12)$ & $10(7-12)$ & $1.2(0.5$ to 2.6$)$ \\
\hline 8 weeks & $8(6-10)$ & $9(4-11)$ & $0.9(0.4$ to 1.9$)$ \\
\hline 12 weeks & $6(3-9)$ & $7(2-10)$ & $1.8(0.8$ to 3.7$)$ \\
\hline 26 weeks & $3(1-7)$ & $3(1-5)$ & $0.9(0.4$ to 1.9$)$ \\
\hline Mechanical ventilation & $30(61 \%)$ & $25(57 \%)$ & $1.3(0.5$ to 3.3$)$ \\
\hline Treatment related fluctuation & $3(6 \%)$ & $5(11 \%)$ & $0.6(0.1$ to 2.7$)$ \\
\hline \multicolumn{4}{|l|}{ Mean MRC sumscore } \\
\hline 4 weeks & $32(26-37)$ & $30(25-36)$ & $1 \cdot 3(-1 \cdot 6 \text { to } 4 \cdot 1)^{*}$ \\
\hline 8 weeks & $37(32-43)$ & $37(32-42)$ & $1 \cdot 2(-1 \cdot 9 \text { to } 4 \cdot 3)^{*}$ \\
\hline 12 weeks & $40(35-46)$ & $43(38-48)$ & $-0.1(-3.2 \text { to } 3.0)^{*}$ \\
\hline 26 weeks & $46(41-52)$ & $51(47-55)$ & $-2 \cdot 0(-4.8 \text { to } 0.8)^{*}$ \\
\hline Duration of mechanical ventilation, days & $26(12-58)$ & $43(9-80)$ & NA \\
\hline Duration of intensive care unit admission, days & $23(8-55)$ & $25(4-77)$ & NA \\
\hline Duration of hospital admission, days & $39(21-67)$ & $30(21-73)$ & NA \\
\hline \multicolumn{4}{|c|}{$\begin{array}{l}\text { Data are median (IQR), } n(\%) \text {, or mean }(95 \% \mathrm{Cl}) \text { unless specified. } \mathrm{SID}=\text { second intravenous immunoglobulin dose. } \\
\mathrm{NA}=\text { not analysed as the assumptions of the linear regression model were not met due to non-normal distributions o } \\
\text { the outcome. ONLS=Overall Neuropathy Limitations Scale. MRC=Medical Research Council. }{ }^{*} \beta \text { coefficient from linear } \\
\text { regression presented here. }\end{array}$} \\
\hline
\end{tabular}

$34 \mathrm{~g} / \mathrm{L}$ [IQR 30-43] vs $17 \mathrm{~g} / \mathrm{L}$ [16-20] at 2 weeks after start of the standard intravenous immunoglobulin dose; appendix p 13). Median serum IgG at 4 weeks was still higher in the SID group than in the placebo group (median $19 \mathrm{~g} / \mathrm{L}$ [IQR 16-22] vs $15 \mathrm{~g} / \mathrm{L}$ [12-18]), but serum IgG concentrations were similar in both groups after 12 weeks.

We compared IgG concentrations in association with thromboembolic events, and found that patients with thromboembolic events did not have higher IgG concentrations after one standard course of intravenous immunoglobulin (mean IgG $26 \mathrm{~g} / \mathrm{L}$ compared with $30 \mathrm{~g} / \mathrm{L}$ in patients without thromboembolic events) or after SID (mean IgG $29 \mathrm{~g} / \mathrm{L}$ compared with $37 \mathrm{~g} / \mathrm{L}$ in patients without thromboembolic events).

\section{Discussion}

This randomised trial did not show a significant clinical benefit of SID in selected patients with Guillain-Barré syndrome who had a predicted poor outcome after a first course of intravenous immunoglobulin. These patients 


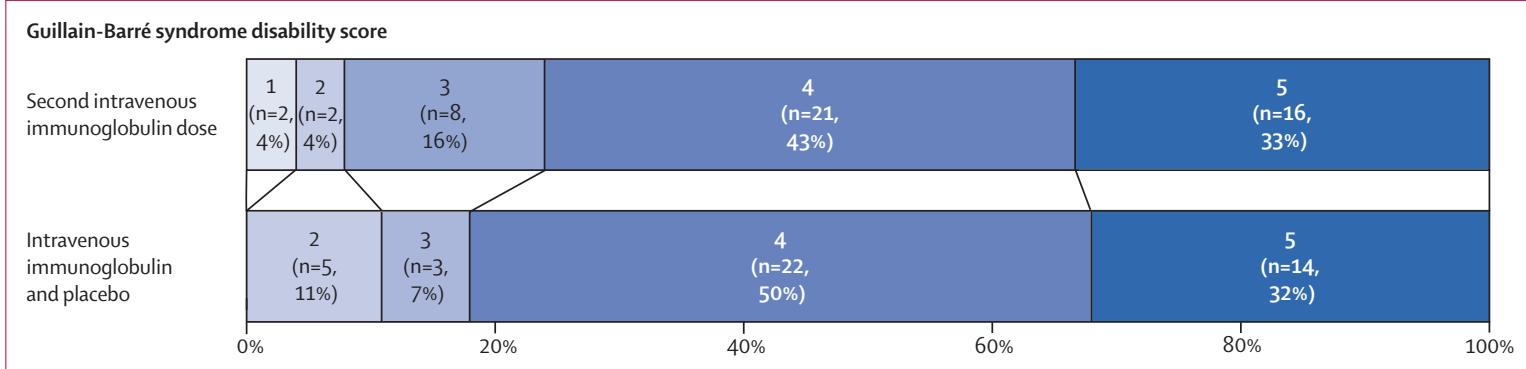

Figure 2: Guillain-Barré syndrome disability score at 4 weeks in the modified intention-to-treat population

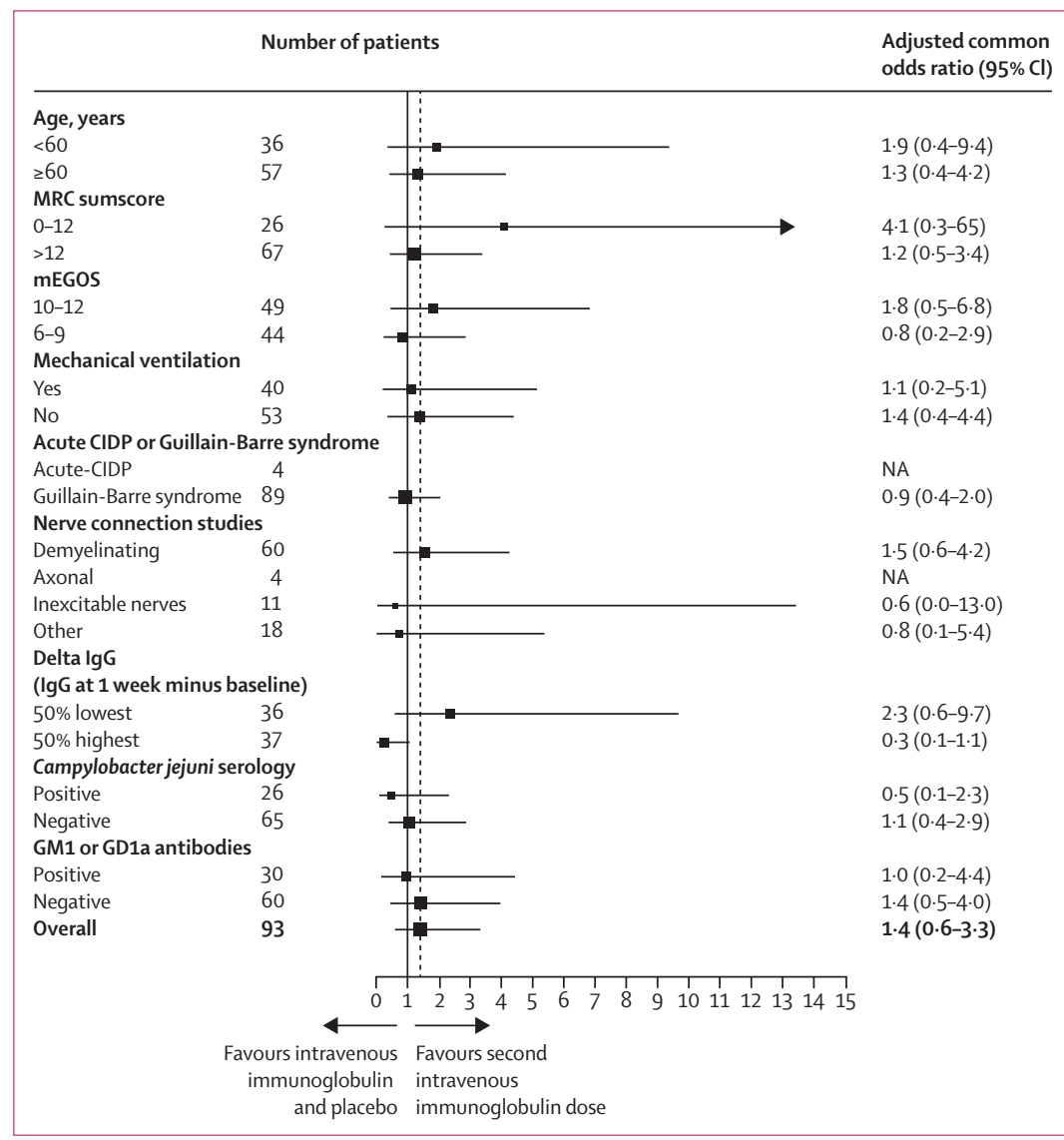

Figure 3: Subgroup analyses

Treatment effect in prespecified subgroup analyses. The outcome is improvement on the Guillain-Barré syndrome disability score at 4 weeks after inclusion (using proportional odds analysis, after covariate adjustment for mEGOS at 1 week). Each dot represents the adjusted common odds ratio, the size of the dot represents the number of patients in each subgroup, and the line represents the $95 \% \mathrm{Cl}$. mEGOS=modified Erasmus GBS Outcome Scale. $\mathrm{NA}=$ not applicable. $\mathrm{CIDP}=$ chronic inflammatory demyelinating polyneuropathy. $\mathrm{MRC}=$ Medical Research Council.

almost all continued to deteriorate at 1 week after the first intravenous immunoglobulin course, and were in a poor neurological condition based on the MRC sumscore and Guillain-Barré syndrome disability score. Our results complement earlier studies, which found that additional immunotherapy (ie, either intravenous immunoglobulin after plasma exchange, six instead of four cycles of plasma exchange, or intravenous methylprednisolone with intravenous immunoglobulin) in the general GuillainBarré syndrome population was not beneficial. ${ }^{28-31} \mathrm{We}$ believe our results can be generalised to the entire GuillainBarré syndrome population even though we studied SID only in those with a poor prognosis.

One of the arguments that suggests a second series of intravenous immunoglobulin might be effective was the observation that a larger increase in serum IgG concentration after intravenous immunoglobulin treatment was related to a more substantial recovery. ${ }^{12,13}$ Our trial showed that SID is able to increase the serum IgG concentration further and for a prolonged period of time than controls (appendix p 13), but this effect did not improve outcome. It might be that a relatively small rise in serum IgG after standard intravenous immunoglobulin treatment is an indicator for disease severity or more rapid intravenous immunoglobulin catabolism, rather than a target for therapy. It seems probable that intravenous immunoglobulin in Guillain-Barré syndrome is predominantly effective very early in the course of disease and that prolonging a high serum IgG concentration provides no additional benefit. This hypothesis could explain both the results of the previous study, in which a higher delta IgG was related to a better outcome than a lower delta IgG, and the results of the current trial. Further research into the mechanisms of the treatment-modifying effect of IgG in Guillain-Barré syndrome is needed.

Another possible reason for not finding a positive effect of a SID could be that the included patients had too severe disease. Too much axonal damage might have already occured at the time of SID administration to find a difference between the groups. However, there was no suggestion of a positive effect of a SID in the subgroup of patients predicted to have a less severe outcome. Instead of repeating the standard dose, doubling the initial intravenous immunoglobulin dose could have resulted in better outcomes, but even more serious adverse events might have occurred as a consequence.

Patients who were given SID had more serious adverse events than those who were given a single intravenous immunoglobulin dose and placebo. Thromboembolic events were reported more often in patients who were given SID than in those who were given placebo. Thromboembolic events are a well known, rare, side-effect of 
intravenous immunoglobulin, and their mechanism is thought to be due to a dose-dependent increase of plasma viscosity. ${ }^{32}$ For this reason, known pre-existing vascular risk factors were a contraindication for randomisation in this trial (appendix p 18). However, other factors such as immobility, dehydration, leucocytosis, and coexisting inflammation can also cause a critical increase of plasma viscosity causing this serious adverse event. Patients with thromboembolic events did not have higher IgG concentrations after one standard course of intravenous immunoglobulin or after SID when compared with patients without these events, and therefore the administration of a second intravenous immunoglobulin course rather than the serum IgG concentration only might be related to these serious adverse events.

Our trial has several limitations. First, the sample size was relatively small, and the estimated odds ratio of 1.45 had wide CIs. However, we believe that our results are valid as the main trial result is the same using modified intention-to-treat or full intention-to-treat analyses; covariate adjustment as prespecified in the statistical analysis plan and protocol did not change the interpretation of the trial; there were no differences between treatment groups for any of the secondary endpoints; and we did not find differences in the subgroup analysis. Although a larger sample size would have increased the statistical power, the trial was powered to find a large treatment effect to improve treatment for this group of severely affected patients, considering that smaller effects would not be clinically meaningful.

Second, some of the baseline variables were unbalanced between groups even though the patients were randomly assigned, which could have affected the outcome. Both age and preceding diarrhoea are known prognostic factors, and correction for these factors (together with baseline MRC sumscore) using covariate adjustment was prespecified in the protocol. Covariate adjustment did not change the interpretation of the trial, as the unadjusted and adjusted common odds ratios were similar. ${ }^{25,26}$

Third, acute-onset chronic inflammatory demyelinating polyneuropathy (CIDP) was diagnosed in four patients during follow-up (two in each group), which is consistent with the frequency reported in the literature in general in trials for the syndrome. ${ }^{11}$ Patients with acute-onset CIDP or with a treatment related fluctuation were given additional intravenous immunoglobulin in the trial (according to established guidelines) ${ }^{11}$ These patients were retained in the main analysis; their exclusion did not affect the results of the trial in a prespecified subgroup analysis. The results of the trial should not change treatment practice of patients with acute-onset CIDP or with treatment related fluctuations.

Fourth, in two patients, the diagnosis was changed (eosinophilic vasculitis in the placebo group and myelopathy in the SID group) shortly after random assignment and initiation of trial medication. Once the alternative diagnosis was made, follow-up stopped, and primary

\begin{tabular}{|c|c|c|}
\hline & $\operatorname{SID}(n=49)$ & Placebo $(n=44)$ \\
\hline \multicolumn{3}{|l|}{ Serious adverse events* } \\
\hline $\begin{array}{l}\text { Any serious adverse event during study } \\
\text { (excluding deaths) } \dagger\end{array}$ & $25(51 \%)$ & $10(23 \%)$ \\
\hline $\begin{array}{l}\text { Any serious adverse event in the first } \\
30 \text { days (excluding deaths) }\end{array}$ & $17(35 \%)$ & $7(16 \%)$ \\
\hline Coronary ischaemia & $1(2 \%)$ & $1(2 \%)$ \\
\hline Asystole & $2(4 \%)$ & 0 \\
\hline Transient ischaemic attack (multiple) & $1(2 \%)$ & 0 \\
\hline Pulmonary embolism & $2(4 \%)$ & 0 \\
\hline Radial artery thrombosis & $1(2 \%)$ & 0 \\
\hline Renal insufficiency & $1(2 \%)$ & $1(2 \%)$ \\
\hline Pneumonia & $12(24 \%)$ & $7(16 \%)$ \\
\hline Other infection & $2(4 \%)$ & $1(2 \%)$ \\
\hline Other serious complications $\ddagger$ & $8(16 \%)$ & $3(7 \%)$ \\
\hline \multicolumn{3}{|l|}{ Other possible related complications $\S$} \\
\hline Haemolytic anaemia & 0 & 0 \\
\hline Blood transfusion 9 & $3(6 \%)$ & 0 \\
\hline \multicolumn{3}{|c|}{$\begin{array}{l}\text { Data are } n(\%) \text {. SID=second intravenous immunoglobulin dose. *Only first events } \\
\text { of a certain type are listed. Patients having multiple events of one type were } \\
\text { counted once. †Odds ratio } 3 \cdot 54(95 \% \mathrm{Cl} 1 \cdot 44-8 \cdot 72) ; \mathrm{p}=0 \cdot 0050 \text {. } ¥ \text { See appendix } \\
\text { (p 21). SProspectively collected from } 2015 \text { onward ( } 24 \text { of } 93 \text { patients). } \\
\text { IFor various reasons other than haemolytic anaemia. }\end{array}$} \\
\hline
\end{tabular}

endpoint analysis was not possible. A full intention-to-treat analysis ( $n=96$, three missing endpoints) resulted in an adjusted common odds ratio of 1.3 (95\% CI $0 \cdot 6-3 \cdot 1)$, which was not different from the modified intention-totreat analysis.

Lastly, our trial had an inclusion period of more than 8 years. This long inclusion period was largely due to the rarity of Guillain-Barré syndrome, and only patients with a poor prognosis were randomly assigned. However, immune treatment of Guillain-Barré syndrome in the Netherlands has not changed over the past 8 years, so we expect that the population recruited in this trial was given the same treatments, despite the long recruitment period.

In conclusion, we found no significant clinical benefit of a second intravenous immunoglobulin course administered shortly after the first standard intravenous immunoglobulin dose in patients with Guillain-Barré syndrome with poor prognosis. Additionally, the group given a second series of intravenous immunoglobulin had more serious adverse events than those given placebo. When looking for better treatments for Guillain-Barré syndrome, we should consider agents acting through a different mechanism than intravenous immunoglobulin, including complement inhibitors (NCT04035135) and IgG degrading enzymes (NCT03943589).

Contributors

CW was responsible for study conception, design, data acquisition, analysis, access and verification of the data, and interpretation and drafting of the manuscript. BCJ and PAvD were responsible for study conception, design, supervision, data acquisition, access and verification 
of the data, and interpretation and drafting of the manuscript. HFL was responsible for study conception, design, access and verification of the data, analysis and interpretation, and drafting of the manuscript. EWS was responsible for study conception, design, and interpretation and drafting of the manuscript. RACH and DRC were responsible for study conception, design, supervision, and interpretation and drafting of the manuscript. All other authors were responsible for data acquisition and for revision of the manuscript. All authors vouch for the fidelity of trial conduct to the protocol, accuracy of outcome reporting, and of adverse events. All authors had full access to all the data in the study and had final responsibility for the decision to submit for publication.

\section{Declaration of interests}

BCJ reports grants from Baxalta, Grifols, CSL-Behring, Annexon, Prinses-Beatrix Spierfonds, Guillain-Barré syndrome/chronic inflammatory demyelinating polyneuropathy (GBS/CIDP) Foundation International, Hansa Biopharma, and EU's Horizon 2020, outside the submitted work. AYD declares that her host institution, the Erasmus MC pays her salary with a fund from Annexon Biosciences (January, 2017) a pharmaceutical company that develops complement inhibitors for Guillain-Barré syndrome. Neither her PhD research nor her employment is contingent on this funding, and AYD has no control over the use of the funds. AYD has also received an honorarium for a lecture from CSL Behring (November, 2018). The money was paid directly to the Erasmus MC and AYD did not financially benefit from this honorarium. KK reports grants from Baxalta now part of Shire/Takeda, outside the submitted work. RH reports grants from Grifols, and GBS/CIDP Foundation International, outside the submitted work. AJvdK reports a grant from CSL Behring, outside the submitted work. FE reports grants from CSL Behring, Kedrion, Terumo BCT, and Takeda Pharmaceutical Company, outside the submitted work. Grants were paid to their institution and were used for investigator-initiated studies within INCbase, an international CIDP registry. He also received consultancy fees from UCB pharma, paid to his institution, outside the submitted work. CGF reports grants from EU's Horizon 2020 research and innovation programme, Marie Sklodowska-Curie grant for PAIN-Net,

Molecule-to-man pain network (grant number 721841), Prinses Beatrix Spierfonds, Grifols, and Lamepro for a trial on intravenous immunoglobulin in small fibre neuropathy, was a member on steering committees and an advisory board for studies in small fibre neuropathy of Biogen/Convergence and Vertex, outside the submitted work. ISJM reports grants from Talecris Talents program, GBS/CIDP Foundation International and FP7 EU program, outside the submitted work; Furthermore, a research foundation at the University of Maastricht received honoraria on behalf of him for participation in steering committees of the Talecris Immune Globulin Intravenous For Chronic Inflammatory Demyelinating Polyneuropathy Study, Commonwealth Serum Laboratories, Behring, Octapharma, LFB, Novartis, Union Chimique Belge, outside the submitted work. UAB reports financial compensation for costs made to include patients in a trial from Novartis, outside the submitted work.

RACH reports personal fees from LFB, Hansa Biopharma, and Sanofi, outside the submitted work and is a medical patron of GAIN. DRC reports consulting for Amgen, Annexon Biosciences, argenx SE, Biotest Pharmaceuticals, Cigna Health Management, CSL Behring, CytomX Therapeutics, Grifols, New Enterprise Associates, Octapharma, Pfizer, Pharnext, Polyneuron Pharmaceuticals, Seattle Genetics, Syntimmune, and UCB. DRC was on the Data Safety Monitoring Board for the following: Alnylam Pharmaceuticals, PledPharma, Momenta Pharma, Hansa Medical, and Mitsubishi Tanabe Pharma Corporation. DRC was involved with technology licensing for AstraZeneca Pharmaceuticals, LP Pharmaceuticals (Xiamen), Genentech, Levicept, Seattle Genetics, Merrimack Pharmaceuticals, and Disarm Therapeutics, outside the submitted work. PAvD reports grants from Sanquin Blood Supply and Prinses Beatrix Spierfonds, during the conduct of the study; and grants from Grifols, Takeda, Annexion, Argenx, Commonwealth Serum Laboratories, Octapharma, and Hansa, outside the submitted work. All grants were paid to the institution and used for investigator-initiated studies. All other authors declare no competing interests.

\section{Data sharing}

In compliance with the General Data Protection Regulation, source data are not available for other researchers as no patient approval has been obtained for sharing coded data. Information about analytic methods, syntax, and output files of statistical analyses will be made available by the corresponding author upon reasonable request.

\section{Acknowledgments}

We thank the following people for their help and advice during the conduct of the SID-GBS trial:

Data monitoring and safety committee: Chair: DWJ Dippel; Member: RQ Hintzen; Independent statistician: SE Hoeks, all from Erasmus MC University Medical Center, Rotterdam, Netherlands.

Trial coordinator: M van Woerkom, Erasmus MC University Medical Center, Rotterdam, Netherlands.

Laboratory investigations: AP Tio-Gillen, W van Rijs; Department of Immunology, Erasmus MC University Medical Center, Rotterdam, Netherlands. S Scherbeijn, AA van der Eijk, Department of Virology, Erasmus MC University Medical Center, Rotterdam, Netherlands; M de Waart, CRB Ramakers, Department of Clinical Chemistry, Erasmus MC University Medical Center, Rotterdam, Netherlands. M Maas, M Batstra, P Herbrink, Department of Microbiology, Reinier de Graaf Hospital, Delft, Netherlands.

Handling trial medication and drug accountability:

M Zoetekouw-Bakker; The Medical Department, Sanquin Plasma Products, Amsterdam, Netherlands.

\section{References}

1 Willison HJ, Jacobs BC, van Doorn PA. Guillain-Barré syndrome. Lancet 2016; 388: 717-27.

2 Asbury AK, Cornblath DR. Assessment of current diagnostic criteria for Guillain-Barré syndrome. Ann Neurol 1990; 27 (suppl): S21-24.

3 Chevret S, Hughes RA, Annane D. Plasma exchange for Guillain-Barré syndrome. Cochrane Database Syst Rev 2017; 2: CD001798.

4 Hughes RA, Swan AV, van Doorn PA. Intravenous immunoglobulin for Guillain-Barré syndrome. Cochrane Database Syst Rev 2014; 9: CD002063.

5 van den Berg B, Walgaard C, Drenthen J, Fokke C, Jacobs BC van Doorn PA. Guillain-Barré syndrome: pathogenesis, diagnosis, treatment and prognosis. Nat Rev Neurol 2014; 10: 469-82.

6 Walgaard C, Lingsma HF, Ruts L, van Doorn PA, Steyerberg EW, Jacobs BC. Early recognition of poor prognosis in Guillain-Barre syndrome. Neurology 2011; 76: 968-75.

7 Verboon C, Doets AY, Galassi G, et al. Current treatment practice of Guillain-Barré syndrome. Neurology 2019; 93: e59-76.

8 Farcas P, Avnun L, Frisher S, Herishanu YO, Wirguin I. Efficacy of repeated intravenous immunoglobulin in severe unresponsive Guillain-Barré syndrome. Lancet 1997; 350: 1747.

9 Godoy DA, Rabinstein A. Is a second cycle of immunoglobulin justified in axonal forms of Guillain-Barré syndrome? Arq Neuropsiquiatr 2015; 73: 848-51.

10 Raphael JC, Chevret S, Harboun M, Jars-Guincestre MC Intravenous immune globulins in patients with Guillain-Barré syndrome and contraindications to plasma exchange: 3 days versus 6 days. J Neurol Neurosurg Psychiatry 2001; 71: 235-38.

11 Ruts L, Drenthen J, Jacobs BC, van Doorn PA. Distinguishing acute-onset CIDP from fluctuating Guillain-Barre syndrome: a prospective study. Neurology 2010; 74: 1680-86.

12 Kuitwaard K, de Gelder J, Tio-Gillen AP, et al. Pharmacokinetics of intravenous immunoglobulin and outcome in Guillain-Barré syndrome. Ann Neurol 2009; 66: 597-603.

13 Walgaard C, Jacobs BC, Lingsma HF, et al. Second IVIg course in Guillain-Barré syndrome patients with poor prognosis (SID-GBS trial): protocol for a double-blind randomized, placebo-controlled clinical trial. J Peripher Nerv Syst 2018; 23: 210-15.

14 Kleyweg RP, van der Meché FG, Schmitz PI. Interobserver agreement in the assessment of muscle strength and functional abilities in Guillain-Barré syndrome. Muscle Nerve 1991; 14: 1103-09.

15 Ang CW, Krogfelt K, Herbrink P, et al. Validation of an ELISA for the diagnosis of recent Campylobacter infections in Guillain-Barré and reactive arthritis patients. Clin Microbiol Infect 2007; 13: 915-22.

16 Jacobs BC, van Doorn PA, Schmitz PI, et al. Campylobacter jejuni infections and anti-GM1 antibodies in Guillain-Barré syndrome. Ann Neurol 1996; 40: 181-87. 
17 Kuijf ML, van Doorn PA, Tio-Gillen AP, et al. Diagnostic value of anti-GM1 ganglioside serology and validation of the INCAT-ELISA. J Neurol Sci 2005; 239: 37-44.

18 van den Berg B, van der Eijk AA, Pas SD, et al. Guillain-Barré syndrome associated with preceding hepatitis $\mathrm{E}$ virus infection. Neurology 2014; 82: 491-97.

19 Hadden RD, Cornblath DR, Hughes RA, et al. Electrophysiological classification of Guillain-Barré syndrome: clinical associations and outcome. Ann Neurol 1998; 44: 780-88.

20 Leonhard SE, Mandarakas MR, Gondim FAA, et al. Diagnosis and management of Guillain-Barré syndrome in ten steps. Nat Rev Neurol 2019; 15: 671-83.

21 Hughes RA, Newsom-Davis JM, Perkin GD, Pierce JM. Controlled trial prednisolone in acute polyneuropathy. Lancet 1978; 2: 750-53.

22 Graham RC, Hughes RA. A modified peripheral neuropathy scale: the Overall Neuropathy Limitations Scale. J Neurol Neurosurg Psychiatry 2006; 77: 973-76.

23 Maas AI, Murray GD, Roozenbeek B, et al. Advancing care for traumatic brain injury: findings from the IMPACT studies and perspectives on future research. Lancet Neurol 2013; 12: 1200-10.

24 Scott SC, Goldberg MS, Mayo NE. Statistical assessment of ordinal outcomes in comparative studies. J Clin Epidemiol 1997; 50: $45-55$.

25 van Leeuwen N, Walgaard C, van Doorn PA, Jacobs BC, Steyerberg EW, Lingsma HF. Efficient design and analysis of randomized controlled trials in rare neurological diseases: an example in Guillain-Barré syndrome. PLoS One 2019; 14: e0211404.
26 Roozenbeek B, Maas AI, Lingsma HF, et al. Baseline characteristics and statistical power in randomized controlled trials: selection, prognostic targeting, or covariate adjustment? Crit Care Med 2009; 37: 2683-90

27 Nguyen TP, Biliciler S, Wahed A, Sheikh K. Occurrence of hemolytic anemia in patients with GBS treated with high-dose IVIg. Neurol Neuroimmunol Neuroinflamm 2014; 1: e50.

28 Plasma Exchange/Sandoglobulin Guillain-Barré Syndrome Trial Group. Randomised trial of plasma exchange, intravenous immunoglobulin, and combined treatments in Guillain-Barre syndrome. Lancet 1997; 349: 225-30.

29 Verboon C, van den Berg B, Cornblath DR, et al. Original research: second IVIg course in Guillain-Barré syndrome with poor prognosis: the non-randomised ISID study. J Neurol Neurosurg Psychiatry 2020; 91: 113-21.

30 van Koningsveld R, Schmitz PI, Meché FG, Visser LH, Meulstee J, van Doorn PA. Effect of methylprednisolone when added to standard treatment with intravenous immunoglobulin for Guillain-Barré syndrome: randomised trial. Lancet 2004; 363: 192-96.

31 The French Cooperative Group on Plasma Exchange in Guillain-Barré Syndrome. Appropriate number of plasma exchanges in Guillain-Barré syndrome. Ann Neurol 1997; 41: 298-306.

32 Kapoor M, Spillane J, Englezou C, et al. Thromboembolic risk with IVIg: Incidence and risk factors in patients with inflammatory neuropathy. Neurology 2020; 94: e635-38. 